\title{
YOGA COMO DISPOSITIVO ERGONÔMICO NA SALA DE AULA DO ENSINO SUPERIOR
}

\author{
Rodrigo de Oliveira Rodrigues - rodrigorobill@gmail.com \\ Universidade Federal de Minas Gerais (UFMG), Departamento de Engenharia Mecânica \\ Av. Pres. Antônio Carlos, 6627 - Pampulha, Belo Horizonte - MG, 31270-901
}

Marcos Vinicius Bortolus - borta@demec.ufmg.br

Resumo: Assim como o indivíduo e a sociedade, a educação também deve se manter em constante transformação. Para tanto, é necessária a transversalidade e o atravessamento entre conhecimentos e práticas. O objetivo deste trabalho é perceber se a prática de Yôga em sala de aula do ensino superior produz efeitos nas atividades ali desenvolvidas. A metodologia das práticas vem das técnicas do Yôga: pranayamas, pavanamuktásanas e mantras. A forma de analisar os efeitos nos estudantes é feita a partir dos conceitos da ergonomia. São utilizados questionários para avaliar os efeitos, sobretudo qualitativos, da prática em sala de aula. Um dos principais efeitos percebidos é o aumento da concentração e da sensação de calma após a prática.

Palavras-chave: Yôga. Educação. Ergonomia. Sala de aula

\section{INTRODUÇÃO}

O presente artigo é parte do trabalho de conclusão de curso desenvolvido na Escola de Engenharia da UFMG. Ele aconteceu devido ao encontro de dois fatores: a conclusão de um curso de Hatha Yôga Integral por um dos autores do trabalho e o conhecimento do outro autor sobre essa prática na educação formal, pois já havia feito o curso de Yoga na Educação com Micheline Flak.

No segundo semestre de 2017, foram iniciadas as práticas na sala de aula. Por um questionamento da Escola de Engenharia sobre a conexão do Yôga com a Engenharia, em uma reunião, um dos autores se lembrou que havia encontrado com a equipe do avião Solar Impulse em seu intercâmbio e que dentro da cabine deste avião o piloto praticava Yôga. $\mathrm{O}$ Solar Impulse mostrou uma conexão possível entre Yôga e engenharia. Durante o vôo, o piloto se utiliza do Yôga como uma forma de regulação ergonômica de suas atividades. $\mathrm{O}$ projeto está tão na fronteira tecnológica que o ser humano também precisa se adaptar e 
otimizar seus próprios processos vitais para conseguir operar esta aeronave. É particularmente interessante pensar nessa fronteira onde a máquina e o humano se encontram, porque é exatamente esse o objetivo da ergonomia: estudar a interação entre o homem e o meio. Em um vídeo (SOLAR IMPULSE AIRPLANE, 2015), o professor de Yôga da equipe, Sanjeev Bhanot, explica que o objetivo com Yôga ali não é reduzir o estresse, mas criar resiliência ao estresse.

Com isto, os objetivos do trabalho se ampliaram. Um objetivo é investigar os efeitos que a prática de Yôga produz nos estudantes de graduação em sala de aula e o outro é apresentá-los a esta técnica milenar que, além de ter o potencial de melhorar sua qualidade de vida no ambiente acadêmico e futuramente no ambiente profissional, pode ter impactos no desenvolvimento de projetos de aeronaves.

\section{REVISÃO BIBLIOGRÁFICA}

\subsection{Yôga}

A arqueologia data o Yôga de 5000 a 3000 a.C. "O aquietamento das ondas mentais é Yôga" (PATANJALI, 2000, p. 3), os Sutras de Patanjali é livro que sistematizou o Yôga e é datado da primeira metade do primeiro milênio d.C. "Equanimidade mental é Yôga." (SATCHIDANANDA, 2000, p. 23) esse é o conceito trazido pelo Bhagavad Gita, livro considerado também referência para o Yõga. Etimologicamente a palavra Yôga vem de "yug" que significa unir, no caso, o Yôga pretende unir mente, corpo e essência. É interessante perceber que esses três pontos de vista estão alinhados, que de alguma forma significam o mesmo. Nesse trabalho pensaremos o Yôga em sua dimensão prática.

Patanjali (2000) diz que para aquietar a mente precisamos da prática e do desapego. Neste caso iremos pela via das práticas, trazendo para a sala de aula algumas dessas práticas. As práticas trazidas serão os pranayamas, mantras e pavanmuktásanas. Além do contato com a prática completa fora da sala de aula, que inclui os ásanas e Yôga nidra.

\subsection{Yôga na educação}

\footnotetext{
"Yôga é um sistema integral de educação, não apenas do corpo e da mente ou do intelecto. O Yôga educa e desenvolve a pessoa inteira - a cabeça, o corpo e o coração." (SWAMI SIVANANDA SARASWATI, apud FLAK; COULON, 2007, p.9 ).
}

Satyananda (2006) fala que durante 20 anos levou o Yôga para as escolas. Porém ele não relata muito sobre como foi esse processo, preocupando-se mais em dizer as influências do Yôga nas crianças em diferentes idades com diferentes técnicas. 
No ocidente o Yôga começou a aparecer na educação através da francesa Micheline Flak em 1985. Ela encontrou na prática uma forma de preparar seus alunos para o aprendizado em suas aulas de inglês. O Yôga e a educação se encontraram por dois fatores: um modelo de educação obsoleto e a globalização (FLAK, 2007). Para justificar ainda mais essa prática no ambiente escolar e com uma perspectiva científica, Flak 2007 comenta que o primeiro indiano a ir para o espaço objetivava estudar o Yôga sem a sensação de gravidade, e que se isso não fosse tão importante os russos não o teriam levado ao espaço.

\subsection{Ergonomia}

A ergonomia, de acordo com a International Ergonomics Association (IEA) (2000), é uma ciência que estuda a interação entre o ser humano e o meio. Para tanto a ergonomia busca aplicar conhecimentos de diferentes campos da ciência, que vão da psicologia à engenharia. Assim, de forma prática, a ergonomia pretende a melhor adaptação da relação do homem com o ambiente produtivo e do homem com o meio e sua vida.

A ergonomia é dividida em física, organizacional e cognitiva. A ergonomia física, como a própria palavra diz, analisa a parte física do trabalho. Ela é responsável por refletir sobre as posturas nas quais os trabalhadores executam suas atividades, se eles têm muito tempo de imobilidade e se carregam muito peso, ou seja, está intimamente ligada à saúde física do trabalhador. Já a ergonomia organizacional se preocupa em refletir se a organização fornece meios para que aquele trabalho seja bem executado. Dessa forma, a análise de layouts de fábrica, posicionamento do posto de trabalho, interação entre diferentes setores é responsabilidade da ergonomia organizacional. Finalmente, a ergonomia cognitiva analisa a parte mental do trabalhador, preocupando-se com processos como a memória, a atenção, o raciocínio e a concentração.

Para Falzon (2007) as tarefas estão relacionadas ao trabalho prescrito pela organização e as atividades são o que é realmente mobilizado para realizar as tarefas. Assim, as atividades mobilizam competências do indivíduo para que ele consiga lidar com a variabilidade da situação de trabalho, uma vez que a atividade é o trabalho real. As competências são habilidades para realizar a atividade. A capacidade de lidar com as variações no ambiente e momento de trabalho estão relacionadas com o conceito de regulação e a análise ergonômica do trabalho. A regulação é o ato de o indivíduo manter a eficiência de seu modo operatório para garantir o objetivo da tarefa e ainda assim preservar sua saúde. Um exemplo de regulação é um palestrante que durante seu discurso faz uma pausa para beber água e depois volta à fala. Além disso, vale citar que a atividade pode ser observável, física, ou inobservável, cognitiva. É a partir dessa perspectiva que é desenvolvida a análise do estudante.

\section{METODOLOGIA}


A disciplina na qual são aplicadas as práticas é aerodinâmica, que é do sexto período do Curso de Graduação em Engenharia Aeroespacial. É uma disciplina teórica com 3 horas-aula, iniciando ás 15 horas indo até as 17 horas e 30 minutos. Na primeira parte da aula, os alunos apresentam as atividades semanais que desenvolvem fora da sala de aula. Na segunda parte da aula, após as práticas de Yôga, discute-se as teorias que têm relação com as atividades apresentadas na primeira parte, ou seja, é uma parte da aula mais reflexiva.

As intervenções com Yôga são praticadas entre a primeira parte e a segunda parte da aula, entre $16 \mathrm{~h}$ e $16 \mathrm{~h} 30 \mathrm{~min}$ logo após um pequeno intervalo. Essas intervenções duram uma média de 20 minutos e começam com as instruções do que será praticado no dia. O total de intervenções durante o semestre são 12 .

A maneira que as práticas são conduzidas leva em conta a faixa etária dos estudantes que no ensino superior já são considerados adultos, ou seja, a condução do processo tem relação com a maturidade dos estudantes. Talvez esta condução pela experiência do autor possa ser aplicada no Ensino Médio, mas não seria adequado para estudantes do ensino fundamental.

Thiruvalluvar, um santo do Sul da Índia diz que "Onde estiver a mente, lá estará também a respiração" (PATANJALI, 2000, p.81). Por esse motivo as primeiras intervenções foram com pranayamas ou exercícios de respiração. A partir da prática desses exercícios é possível acalmar a respiração e uma respiração calma traz uma mente calma. Seguindo-se por duas intervenções com exercícios para as articulações ou pavanamuktásanas, que, de acordo com Flak (2007) elimina toxinas do corpo. Esses exercícios ajudam a desenvolver a concentração e promovem relaxamento (SATYANANDA, 2006). As intervenções seguintes foram com mantras, que são vocalizações em sânscrito e literalmente significa "o que protege a mente". A mente não é nada mais que pensamentos (FRAWLEY 2018). Vygotsky (1989) cita que o pensamento é linguagem, mas nem toda linguagem é pensamento. Um exemplo disso é quando existe uma repetição em nossa mente, como o refrão de uma música ou um poema. Para o autor, o indivíduo só pode possuir uma linguagem em sua mente, sendo assim, se repete uma mesma linguagem não pensa. Logo, a partir do momento que se pratica o mantra a pessoa começa a entender esse estado de não pensamento, que lhe traz consciência dos pensamentos e logo da mente. Além disso, para que os estudantes compreendessem o Yôga para além das intervenções foi feita uma prática completa em outro ambiente, na qual eles tiverem contato com os ásanas (posturas) e Yôga nidra (relaxamento). Na tabela 1, pode-se ver quais as técnicas utilizadas em cada intervenção.

TABELA 1 - Cronograma de intervenções

\begin{tabular}{|c|c|c|}
\hline & Explicação & Prática \\
\hline Intervenção 1 & $\begin{array}{l}\text { Objetivos do trabalho de } \\
\text { conclusão de curso e seu contexto }\end{array}$ & $\begin{array}{l}\text { - respiração abdominal com } \\
\text { quadrada }\end{array}$ \\
\hline intervenção 2 & O que é Yôga? & - respiração completa \\
\hline Intervenção 3 & $\begin{array}{l}\text { "Onde estiver a mente, lá estará } \\
\text { também a respiração" }\end{array}$ & $\begin{array}{l}\text { - } \text { respiração completa } \\
\text { - } \text { respiração polarizada }\end{array}$ \\
\hline
\end{tabular}




\section{"Os desafios para formar hoje o engenheiro do amanhã"}

\begin{tabular}{|c|c|c|}
\hline Intervenção 4 & $\begin{array}{l}\text { Vídeo do Yôga dentro do Solar } \\
\text { Impulse }\end{array}$ & $\begin{array}{l}\text { - respiração completa } \\
\text { - Kapalabhakti }\end{array}$ \\
\hline Intervenção 5 & & $\begin{array}{l}\text { - } \text { Respiração abdmonial com } \\
\text { quadrada } \\
\text { - } \text { respiração completa } \\
\text { - } \text { respiração polarizada } \\
\text { - Kapalabhakti }\end{array}$ \\
\hline Intervenção 6 & $\begin{array}{l}\text { Relação entre articulações e as } \\
\text { tensões que elas podem acumular } \\
\text { (referência Michelini Flak) }\end{array}$ & $\begin{array}{l}\text { - pavanmuktásana para ombros } \\
\text { - pavanmuktásana para pescoço }\end{array}$ \\
\hline Intervenção 7 & & $\begin{array}{l}\text { - pavanmuktásana } \\
\text { - para tornozelos } \\
\text { - pavanmuktásana para punhos }\end{array}$ \\
\hline Intervenção 8 & $\begin{array}{l}\text { "Pensamento e Linguagem" } \\
\text { Vygotsky }\end{array}$ & - mantra $\hat{O} M$ \\
\hline Intervenção 10 & & $\begin{array}{l}\text { Prática completa } \\
\text { - ásanas } \\
\text { - respiração abdminal com } \\
\text { quadrada, } \\
\text { - mantra Hari ÔM, } \\
\text { - pavanmukstanas } \\
\text { - Yôga nidra }\end{array}$ \\
\hline intervenção 11 & Aplicação dos questionários & \\
\hline Intervenção 12 & $\begin{array}{l}\text { Roda de conversa sobre as } \\
\text { práticas }\end{array}$ & \\
\hline
\end{tabular}

Os questionários foram aplicados com o objetivo de investigar quais os efeitos da prática para os estudantes. É possível ver o roteiro do questionário na tabela 2. Na análise destes questionários buscou-se uma abordagem quantitativa, percebendo-se uma maior recorrência de algumas palavras (e seus sinônimos), e uma abordagem qualitativa observando-se algumas respostas que chamam a atenção para diferentes efeitos das práticas.

TABELA 2 - Questionário

\begin{tabular}{|c|c|}
\hline Pergunta 1 & $\begin{array}{c}\text { O que você percebe em si logo após a prática? Compare seu estado antes e } \\
\text { depois da prática. (Sentimentos, emoções, percepção, atenção, facilidades e } \\
\text { dificuldades) }\end{array}$ \\
\hline Pergunta 2 & O que você percebe na sala de aula como um todo após a prática? \\
\hline Pergunta 3 & Você já havia praticado algum tipo de meditação? \\
\hline
\end{tabular}




\begin{tabular}{|c|c|}
\hline Pergunta 4 & $\begin{array}{c}\text { Você chegou a fazer alguma pesquisa sobre Yôga ou meditação após o início das } \\
\text { práticas? }\end{array}$ \\
\hline Pergunta 5 & Deixe aqui seus comentários e/ou sugestões sobre as práticas. \\
\hline
\end{tabular}

\section{DISCUSSÃO E RESULTADOS}

As intervenções aconteceram em quatro semestres, dos quais três tiveram os questionários respondidos. O total de questionários respondidos foram 29. As práticas não eram obrigatórias. Em todos os semestres a maioria da turma participou das práticas. Em dois semestres apenas um quinto não participou e em um dos semestres um terço.

\subsection{Análise das tarefas e atividades do estudante}

Ao se pensar a aula de aerodinâmica teórica é possível imaginar algumas tarefas prescritas, são elas: fazer as atividades propostas fora da sala, apresentar as atividades propostas, refletir em roda sobre os conceitos desenvolvidos nas atividades e elaborar programas de computador. Dentro dessas tarefas, o que realmente é mobilizado pelos estudantes fisicamente e cognitivamente, ou seja, as atividades são: capacidade de estar sentado em uma postura adequada por uma média de 100 minutos, escrever, ler, falar em público, ficar em pé, conversar entre si, elaborar conceitos, digitar no computador.

Após essa análise é possível ver sentido nas palavras mais recorrentes. Atenção e concentração são sinônimos e a concentração é esperada, porque Sivananda (2018) diz que antes da meditação vem a concentração. A calma faz parte do processo de aquietamento das ondas mentais e o relaxamento é benefício comum da prática de Yôga. Porém, além dessas, também apareceram recorrentes as palavras: tranquilidade e foco. Estas são sinônimos de calma e concentração, respectivamente. Na FIGURA 2 mostra-se a recorrência destas palavras. Na FIGURA 3 se agrupa as palavras que possuem o mesmo significado.

FIGURA 2 - Recorrência das palavras

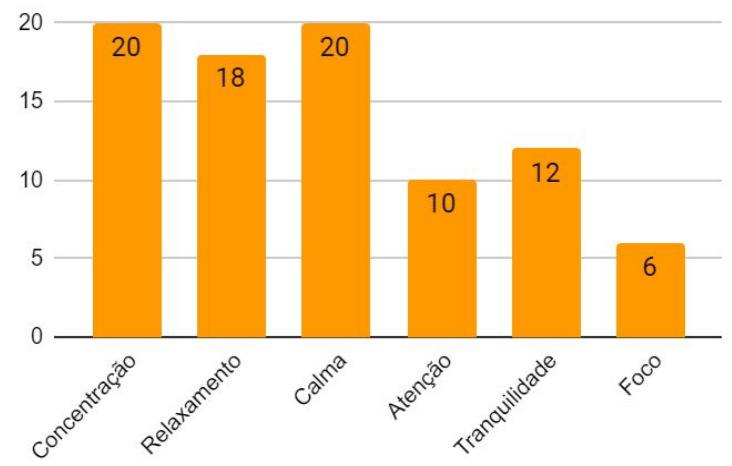

Fonte: Dados coletados nos questionários
FIGURA 3 - Recorrência das palavras com sinônimos

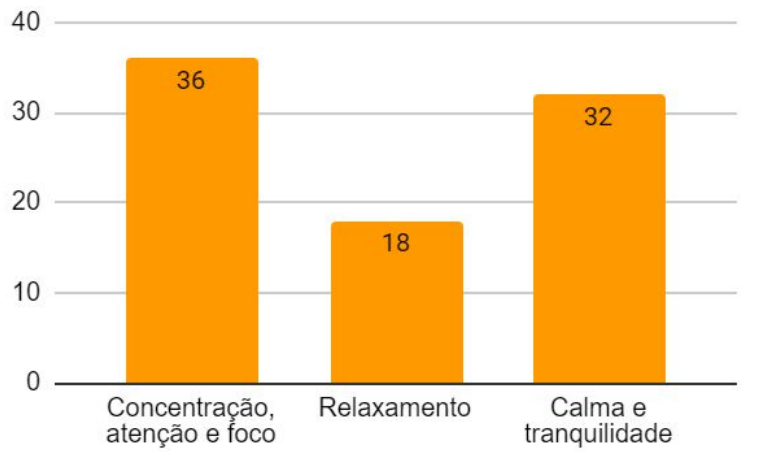

Fonte: Dados coletados nos questionários 
Assim a partir das palavras mais utilizadas pelos estudantes é possível notar que a prática age de forma a melhorar a percepção para as capacidades necessárias para que eles consigam fazer suas atividades. Além disso, algumas respostas também são muito relevantes para perceber os efeitos da prática. Podemos observar alguns exemplares, devido ao número reduzido de páginas do artigo, dessas respostas dos estudantes na TABELA 3.

TABELA 3 - Respostas aos questionários

\begin{tabular}{|c|c|c|}
\hline PERGUNTAS & ESTUDANTE & RESPOSTAS \\
\hline Pergunta 1 & Estudante 1 & $\begin{array}{l}\text { "Sinto um relaxamento muito grande e uma boa } \\
\text { revigoração. É como se eu começasse a aula novamente" }\end{array}$ \\
\hline & Estudante 2 & $\begin{array}{l}\text { "Sempre no inicio das práticas, principalmente as } \\
\text { primeiras, eu tinha certa dificuldade em me concentrar e } \\
\text { acabava sentindo efeitos pouco perceptíveis. Com a } \\
\text { continuidade, passei a perceber que eu sentia logo após a } \\
\text { prática uma sensação de conforto, descanso, calma muito } \\
\text { grande. Essa sensação me gerava um relaxamento que } \\
\text { sempre aumentava o meu rendimento posterior e reduzia a } \\
\text { sensação de sono e cansaço." }\end{array}$ \\
\hline & Estudante 3 & $\begin{array}{l}\text { "Bastante calma, por vezes ao final um pouco de } \\
\text { tontura. Percebo também menos ansiedade." }\end{array}$ \\
\hline & Estudante 4 & $\begin{array}{l}\text { "Percepção maior das áreas do corpo envolvidas, } \\
\text { bem como algumas não (ombro, coluna e pescoço com a } \\
\text { postura ereta). Sentimento de relaxamento moderado após } \\
\text { o fim de algumas práticas. Um pouco nervoso pela } \\
\text { incapacidade de acompanhar algumas práticas } \\
\text { respiratórias (similar a exaustão). }\end{array}$ \\
\hline & Estudante 5 & $\begin{array}{l}\text { "Após a prática, percebo uma espécie de } \\
\text { "restauração" da capacidade de prestar atenção. } \\
\text { Também sinto relaxamento e alivio de tensões." }\end{array}$ \\
\hline Pergunta 2 & Estudante 6 & $\begin{array}{l}\text { "Em suma o que foi falado acima, depende do caso. } \\
\text { Em algumas mais calma, em outras mais atenção e em } \\
\text { alguns sono." }\end{array}$ \\
\hline Pergunta 5 & Estudante 7 & $\begin{array}{l}\text { "A realização das práticas durantes as aulas } \\
\text { influenciaram positivamente em meu desempenho de } \\
\text { aprendizado e atenção em sala e fora." }\end{array}$ \\
\hline & Estudante 8 & $\begin{array}{l}\text { "Acho uma boa experiência pessoal, tem me ajudado } \\
\text { com o rendimento na sala" }\end{array}$ \\
\hline
\end{tabular}




\begin{tabular}{|l|l|l|}
\hline Estudante 9 & $\begin{array}{l}\text { "Acho que as práticas de respiração são muito } \\
\text { eficazes para elevar a produtividade na sala e reduzir o }\end{array}$ \\
& $\begin{array}{l}\text { estresse dos alunos. Ter feito essas práticas mudou } \\
\text { minhas impressôes sobre o Yôga e passei a praticar } \\
\text { frequentemente. Para mim os melhores ex. são de } \\
\text { respiração quadrada e os de Yôga nidra." }\end{array}$ \\
\hline
\end{tabular}

\subsection{Análise das respostas}

A partir do Estudante 1 em sua resposta à Pergunta 1 é possível observar na resposta que a prática funcionou como uma regulação na capacidade do estudante assistir a aula e em seu vigor. Além do Estudante 1, o Estudante 5 também indica em sua resposta que a prática funciona com uma forma de regular as atividades através da modificação da atenção.

A resposta do Estudante 9 demonstra que a prática foi além da sala de aula, numa perspectiva de capacitar o estudante a utilizá-la em outros momentos, como uma ferramenta de regulação de suas atividades no dia-a-dia.

O Estudante 6 demonstra algumas dificuldade ou desconforto em executar as práticas relacionadas a respiração. É interessante refletir se este estudante já tinha consciência da limitação de suas respirações ou se ela se tornou consciente através da prática. O Estudante 3 observa um certo efeito de tontura e diminuição de pressão arterial. Esses efeitos relatados por 3 são comuns e acontecem sob a prática de exercícios de respiração, tanto que os estudantes são orientados sobre a possível tontura durante a condução de algumas práticas.

O Estudante 6 relata sono após a prática. Por outro lado, os estudantes relatam em roda de conversa que não tem tido sono satisfatório. Assim, não se pode afirmar que a o sono tenha uma relação direta com as práticas realizadas.

As respostas dos estudantes 2, 4, 7, 8, 9 demonstram uma "sensação da melhoria do desempenho e rendimento" dentro da sala de aula. Quando são analisadas as palavras que foram mais encontradas nos questionários, é possível perceber que elas estão diretamente ligadas à regulação da atividade, e logo, "sensação de eficiência" enquanto executa a mesma. Por esse motivo existe a "sensação de aumento da produtividade e rendimento" dentro da sala.

O professor da disciplina, que também participou das práticas, relata resultados semelhantes. Ele aponta efeitos de calma e relaxamento em si e a percepção da turma mais concentrada e silenciosa, ou seja, mais preparada para a parte reflexiva da aula.

\section{CONSIDERAÇÕES FINAIS}

A partir da análise dos resultados é possível perceber em que aspectos a prática do Yôga em sala de aula de uma disciplina do ensino superior afeta os estudantes. Nas condições 
explicitadas aqui de emprego do Yôga, percebemos que a prática contribuiu no sentido de aumentar a concentração, a calma e o relaxamento dos estudantes. Estes aspectos trazem "sensações de melhoria de produtividade e rendimento". Estas observações foram colocadas entre aspas, pois não se pretendeu aqui conectar as práticas diretamente a aspectos pedagógicos ou com objetivos pedagógicos da disciplina em questão. O objetivo das práticas estava ligado ao favorecimento e à melhoria da qualidade de vida na sala de aula durante as atividades, ou seja, para os mesmos objetivos pedagógicos os resultados apontam que eles foram alcançados com maior bem-estar e menor esforço (talvez se possa dizer com um melhor rendimento energético, ou seja, fazendo a mesma atividade com um gasto menor de energia). É como fazer uma caminhada para se chegar a um determinado local. Dependo do jeito e da preparação pode-se chegar ao mesmo ponto mais ou menos fatigado, com ou sem dores. Logicamente, a médio e longo prazo certos males como dores ou o estresse podem piorar o nosso rendimento em determinadas atividades ou mesmo inviabilizar a sua prática. Assim, pode-se dizer que o Yôga contribui para melhorar as condições de desenvolvimento das atividades pelos estudantes. Para se fazer uma análise do ponto de vista estritamente pedagógico seria necessário mais tempo de pesquisa com grupos de controle e aprofundar em estudos sobre a relação entre a cognição e o funcionamento da mente.

Como resultados das práticas de Yôga em sala de aula, além do que foi descrito acima, podemos destacar: i) o despertar dos alunos para o cuidar de si, para processos e práticas que podem melhorar a sua qualidade de vida e o seu bem-estar envolvendo a sua saúde física e a sua saúde mental; ii) a valorização pelos estudantes de conhecimentos de outras áreas e outras tradições, além dos conhecimentos científicos, que podem ser importantes para a sua capacitação profissional e humana. Sobre este último ponto a Universidade Federal de Minas Gerais, através de sua Pró-Reitoria de Graduação, iniciou em 2015, a Formação Transversal em Saberes Tradicionais. Nesta formação as disciplinas são ministradas por mestres de comunidades tradicionais, comumente indígenas e quilombolas e podem ser cursadas por alunos de qualquer curso da universidade (PROGRAD, 2020).

\section{REFERÊNCIAS}

FALZON, Pierre. Ergonomia. São Paulo, Editora Blucher, 2007. 640p.

FLAK, Micheline; COULON, Jacques. Yôga na educação, Florianopólis, Comunidade do saber la ed, 2007.

FRAWLEY, David. Uma visão ayurvédica da mente, São Paulo, Editora Pensamento, 2018.

PATANJALI. Yôga Sutra ( Transcrito e comentado por Swami Satchidananda). Belo Horizonte: Editora e Gráfica Del Rey, 2000. 
PROGRAD. Catálogo das Atividades Acadêmicas Curriculares de Formação Transversal. Universidade Federal de Minas Gerais, Belo Horizonte, MG, 2020. Disponível em

https://www2.ufmg.br/prograd/prograd/Pro-Reitoria-de-Graduacao/Estudante/Formacao-Tran sversal/Matricula-nas-Atividades-Academicas-Curriculares-de-Formacao-Transversal. Acesso em: 24 set. 2020.

SATCHIDANANDA, Swami. Vivenciando o Gita: O Bhagavad Gita completo / Com comentários para leitores modernos, Belo Horizonte, MG, EGL Editores, 2016.

SATYANANDA, Swami. Yôga e Educação para Crianças, Belo Horizonte, Editora Satyananda Yôga Center, 2006.

SIVANANDA, Swami. Mind-Its mysteries and control, Tehri-Garhwal, Uttarakhand, Himalayas, Índia, publicado por The Divine Life Society 2018.

SOLAR IMPULSE AIRPLANE. Yoga within Solar Impulse 2. Extraído da transmissão dos bastidores do evento, uma transmissão da Radio Télévision Suisse, 23 de dezembro de 2015. Disponível em: https://www.youtube.com/watch?v=2bHMWXii6n0. Acesso em: 5 out. 2019.

VYGOTSKY, Lev Semyonovich. Pensamento e Linguagem, São Paulo, Editora Martins Fontes 1989.

\title{
YOGA AS ERGONOMIC TOOL IN THE CLASSROOM AT HIGHER EDUCATION
}

\begin{abstract}
Like the individual and society, education must be constantly changing. Therefore, transversality and the intersection between knowledge and practice is required. The goal of this final paper is to realize if Yoga practises in higher education classroom cause effects on the activities developed there. The methodology of the practices come from the Yoga techniques: pranayama, pavanmuktásanas and mantras. The student is analyzed by the ergonomic concepts. The main effect realized is the increase of concentration and feeling of calmness of the students after practice.
\end{abstract}

Keywords: Yoga, education, ergonomics, classroom 